\title{
Relationship between Cardiofemoral Index and the plasma concentration of brain natriuretic peptide in anemic fetuses associated with $\mathrm{Rh}$ alloimmunization
}

Ana Luíza Penido Ferreira •

Zilma Silveira Nogueira Reis · Jacqueline Braga •

Henrique Vitor Leite · Antônio Carlos Vieira Cabral

Published online: 31 December 2008

(C) Springer-Verlag 2008

\section{Erratum to: Arch Gynecol Obstet}

DOI 10.1007/s00404-008-0728-y

The author would like to make following corrections in his online published article.

Under the "Materials and methods" section, first line of the text instead of "A cross-sectional study was carried out from September $\mathbf{2 0 0 3}$ to May 2007 at the Fetal Medicine Center of the Federal University of Minas Gerais, Brazil", it should read as "A cross sectional study was carried out from September 2001 to May 2007 at the Fetal Medicine Center of the Federal University of Minas Gerais, Brazil".

Under the "Results" section, the second line of the text instead of "Anemia was severe in $\mathbf{1 7}(\mathbf{5 0 \%})$ fetuses, mild in $9(\mathbf{2 6 . 4 7 \%})$ and in 8 cases $(\mathbf{2 3 . 5 3 \%})$ the fetuses were not anemic" it should read as "Anemia was severe in $\mathbf{1 7}$ $(52 \%)$ fetuses, mild in $8(24 \%)$ and in 8 cases $(24 \%)$ the fetuses were not anemic".

The online version of the original article can be found under doi:10.1007/s00404-008-0728-y.

\footnotetext{
A. L. P. Ferreira $(\bowtie) \cdot$ Z. S. N. Reis · J. Braga · H. V. Leite A. C. V. Cabral

Fetal Medicine Center, Obstetrics and Gynecology Department, Federal University of Minas Gerais, Belo Horizonte, Brazil e-mail: anapenido@oi.com.br
}

\footnotetext{
A. L. P. Ferreira · Z. S. N. Reis · J. Braga $\cdot$ H. V. Leite

A. C. V. Cabral

Avenida Alfredo Balena, 190-4. andar,

CEP 30130100 Belo Horizonte, Brazil
} 